\title{
Effects of particle size, bimodality and heat treatment on mechanical properties of pumice reinforced aluminum syntactic foams produced by cold chamber die casting
}

\author{
*Çağın Bolat, İsmail Cem Akgün, Ali Gökşenli \\ Faculty of Mechanical Engineering, Istanbul Technical University, 34437, Istanbul, Turkey
}

\begin{abstract}
In recent years, metal matrix syntactic foams (MMSFs) have become highly attractive owing to their unique physical, microstructural and mechanical features. Due to their promising potential for different industrial areas like automotive, aviation, and defense, these advanced engineering materials can also be evaluated as serious alternatives to particle reinforced metallic composites and conventional metallic foams. Differently from previously reported laboratory scaled techniques in the literature, this experimental effort focuses on the feasibility of MMSF manufacturing via a fully automated and industrial-based cold chamber die casting technique. Accordingly, 1-2 mm, 2-4 mm, and bimodal (50vol.\%) natural-based pumice filled aluminum syntactic foams were manufactured utilizing a purpose-made casting machine. Physical, macroscopic, and microscopic examinations show that all of the fabricated samples display perfect matrix/filler harmony. Average density levels of fabricated syntactic foams range between 1.50 and $1.80 \mathrm{~g} \cdot \mathrm{cm}^{-3}$ depending upon the pumice particles size interval. To assess mechanical responses, quasi-static compression tests were performed. Furthermore, half of the foam samples were subjected to heat treatment to explore possible influences of aging on the compressive features and damage modes. Results indicate that although the heat treatment enhances the compressive strength, plateau stress, and energy absorption properties of the fabricated foams, it changes damage mode of the samples by causing brittle dominant deformation.
\end{abstract}

Key words: pumice; cold chamber die casting; syntactic foam; bimodality; damage characteristic
CLC numbers: TG146.21
Document code: $\mathrm{A}$
Article ID: 1672-6421(2021)06-529-12

\section{Introduction}

Syntactic foams (SFs) are versatile engineering materials which consist of polymer/metal matrix and thin-walled hollow ceramics or cellular-structured oxides ${ }^{[1,2]}$. Although polymer matrix syntactic foams (PMSFs) have been investigated by many researchers and their commercial usage has been underway for some time, this case is not valid for metal matrix syntactic foams (MMSFs), and fabrication efforts have only remained on a laboratory scale. In literature, MMSFs are not only classified as a subgroup of conventional closed-cell metallic foams, but also interpreted as advanced particle reinforced composite

\section{*Çağin Bolat}

Male, born in 1989, a Ph. D candidate and research assistant in the Istanbul Technical University. His research interests mainly focus on metal matrix syntactic foams, casting technologies, and aluminum alloys. He has published eleven papers in different indexes such as $\mathrm{SCl}, \mathrm{ESCl}$, Scopus, etc.

E-mail: caginbolat@itu.edu.tr

Received: 2021-07-20; Accepted: 2021-09-09 foams ${ }^{[3]}$. Due to their perfect energy absorption capacity ${ }^{[4]}$, good elongation ${ }^{[5]}$, weight reduction potential ${ }^{[6]}$, and high impact resistance ${ }^{[7]}$, MMSFs have become attractive in recent years for many different industrial areas such as automotive (crash boxes assembled in the front panel), aerospace (fuselage parts on the airplane), marine (submarine hulls), and defense (special armors placed in the core of sandwich composites for ballistic performance).

Compared to other alternatives like iron ${ }^{[8]}$, zinc ${ }^{[9]}$, magnesium ${ }^{[10]}$, and titanium ${ }^{[11]}$, aluminum alloys (especially the A356 system ${ }^{[2,3]}$ ) are the most preferable metals as a matrix due to their widespread usage, low density, and good casting ability. Furthermore, when reinforcement ceramics are analyzed, two different models are noticed: thin-walled hollow spheres and porous/cellular-structured particles. In the category of hollow spheres, thin-walled $\mathrm{Al}_{2} \mathrm{O}_{3}, \mathrm{SiC}$, and glass spheres have been utilized by different investigation groups ${ }^{[12-15]}$. Even though this kind of special fillers display sufficient 
mechanical properties, their manufacturing costs are high as a result of the sophisticated fabrication procedures. As for porous/cellular particles, the fly ash cenospheres ${ }^{[16,17]}$, which are by-products of the burning process at coal utilized energy facilities, have been frequently selected by reason of cheapness. Expanded perlite and expanded glass granules are other options to obtain syntactic characteristics in the metal matrix, and some researchers emphasized that these expanded granules could be cost-effective in comparison with ceramic hollow spheres ${ }^{[18,19]}$. Besides, to determine its probable influence on the mechanical and physical properties of the fabricated syntactic foams, lightweight expanded clay spheres have been introduced as a new filler material by dissimilar research teams ${ }^{[20,21]}$.

There are two main methods for MMSF fabrication according to literature: infiltration casting and dispersion-based mixing ${ }^{[22]}$. Some valuable investigations were conducted via infiltration casting and stir casting in recent years. For instance, Orbulov et al. ${ }^{[23]}$ manufactured expanded perlite/A356 foams through inert gas infiltration casting to study the fatigue behavior of the produced samples. Knapek et al. ${ }^{[24]}$ applied similar gas pressure assisted infiltration technique to fabricate hollow glass reinforced commercially purity Al and AlSi12 foams. In another effort, Pan et al. ${ }^{[25]}$ fabricated $\mathrm{Al}_{2} \mathrm{O}_{3} / \mathrm{AA} 7055$ syntactic foams by traditional gravity infiltration casting and found that heat treatment improved compressive properties. Puga et al. ${ }^{[26]}$ developed vibration-assisted gravity casting to obtain expanded clay filled AlSi7Mg foams and reported that as the particle density increased, the yield strength of the samples increased. Fiedler et al. ${ }^{[27]}$ produced tube-filled expanded perlite reinforced zinc-aluminum alloy (ZA27) syntactic specimens by means of a specially designed counter gravity (backward) infiltration casting system. Park et al. ${ }^{[28]}$ utilized a dispersionbased stirring method (at $800{ }^{\circ} \mathrm{C}$ ) to produce cenosphere filled Al-7Mg syntactic foams and results showed samples possessing a filler volume fraction of $50 \%$ could be created. Similarly, Sahu et al. ${ }^{[29]}$ found that cenosphere/Al 2014 foams could be manufactured via stir-casting and the foam density was $2 \mathrm{~g} \cdot \mathrm{cm}^{-3}$ in average. Broxtermann et al. ${ }^{\left[{ }^{30]}\right.}$ carried out a comparative study to scrutinize the difference between infiltration and stirring techniques and found that infiltrated foams displayed density gradient while this situation was not observed in the stir casting foams. Moreover, the researchers emphasized that stir casting samples had superior mechanical properties than infiltrated samples due to their higher foam density values. Aside from the well-known methods, some alternative powder metallurgical ways have also been applied for MMSF manufacturing, in particular with micron-scale fillers. Vogiatzis et al. ${ }^{[31]}$ followed a cold powder compaction technique for the fabrication of $75 \mu \mathrm{m}$ cenosphere reinforced commercially purity $\mathrm{Al}$ syntactic foams. Akinwekomi et al. ${ }^{[32]}$ synthesized 100-250 $\mu \mathrm{m}$ fly-ash cenosphere filled aluminum syntactic foams through microwave sintering, and pointed out that microwave sintering shortened process duration and blocked undesired chemical reactions.

The cold chamber die casting process is an industrial-focused manufacturing method by which metallic alloys like Al and $\mathrm{Mg}$ can be cast ${ }^{[34,35]}$. Compared to other casting techniques, it provides many important advantages to the manufacturers. High production rate, compatibility with automation system, accurate dimension, high quality surface, flawless casting of thinner sections, minimum need for secondary operation, and unproblematic casting of metals having poor fluidity are asserted as remarkable superiorities of this technique ${ }^{[36]}$.

On the road to applications of the MMSFs, fabrication technique has a vital role. Previously applied lab-scaled methods have only focused on small-sized and simple-geometry parts. However, in this work, industrial-focused cold chamber die casting technology was introduced for the fabrication of pumice/ AA7075 syntactic foam. A specially designed and automatically controlled casting machine including an inclined sprue channel, a horizontal shot chamber, and a two-piece steel die was used. AA7075 syntactic samples reinforced with 1-2 mm small-sized, 2-4 mm big-sized, and bimodal (50vol.\% small-sized pumice and 50vol. $\%$ big-sized pumice) low-cost pumice were fabricated to investigate the influences of particle size on the physical and mechanical properties. Fabricated samples were inspected in macro and micro scales to explore the effectiveness of the proposed manufacturing method. Quasi-static compression tests were conducted to test the syntactic characteristics of the foams, such as elongation, energy absorption and plateau behavior. Furthermore, half of the samples were subjected to T6 heat treatment to examine the effect of aging treatment on the mechanical properties and damage modes.

\section{Experimental procedure}

Due to its good ductility, high strength, sufficient toughness, widespread usage in the industry, and heat treatment applicability, AA7075 alloy was selected as a matrix material. Bar-shaped (60 $\mathrm{mm}$ in diameter and $150 \mathrm{~mm}$ in length) metal blocks were supplied from Güray Aluminum Limited Company (Istanbul, Turkey). Chemical compositions of the AA7075 blocks are shown in Table 1.

Table 1: Chemical compositions of AA7075 alloy (wt.\%)

\begin{tabular}{ccccccccc}
$\mathrm{Zn}$ & $\mathrm{Mg}$ & $\mathrm{Cu}$ & $\mathrm{Fe}$ & $\mathrm{Cr}$ & $\mathrm{Mn}$ & $\mathrm{Si}$ & $\mathrm{Ti}$ & $\mathrm{Al}$ \\
\hline 5.68 & 2.39 & 1.39 & 0.21 & 0.21 & 0.18 & 0.18 & 0.034 & Bal.
\end{tabular}

Pumice is a self-porous, cellular-structured, and $\mathrm{SiO}_{2}$ based natural ceramic that forms after rapid cooling of liquid lava resulting from volcanic eruptions ${ }^{[33]}$. Usually, as an aggregate, it benefits to reduce total construction weight and lighten concrete. In this work, small-sized (1-2 mm), big-sized (2-4 mm), and bimodal (50vol.\%) pumice particles were used as space holders in the AA7075 matrix. All particles were supplied from Miner Mining Limited Company (Nevsehir, Turkey). The chemical composition of the pumice particles is given in Table 2 . In addition, macro and micro images of these sponge-like particles are shown in Fig. 1. 
Table 2: Chemical composition of pumice particles (wt.\%)

$\begin{array}{cccccccc}\mathrm{SiO}_{2} & \mathrm{Al}_{2} \mathrm{O}_{3} & \mathrm{Fe}_{2} \mathrm{O}_{3} & \mathrm{MgO} & \mathrm{CaO} & \mathrm{Na}_{2} \mathrm{O} & \mathrm{K}_{2} \mathrm{O} & \mathrm{TiO}_{2} \\ 65 & 11.67 & 1.75 & 0.15 & 0.55 & 4.12 & 4.1 & 0.03\end{array}$

From Fig. 1, it can be seen that pumice particles have unique and random pore structures compared to other filler materials frequently used in syntactic studies. There are major gaps (in the forms of circular and tubular) on the outer surface [Fig. 1(b)], but solid sections exhibit textured and rough structures [Fig. 1(c)]. (a)
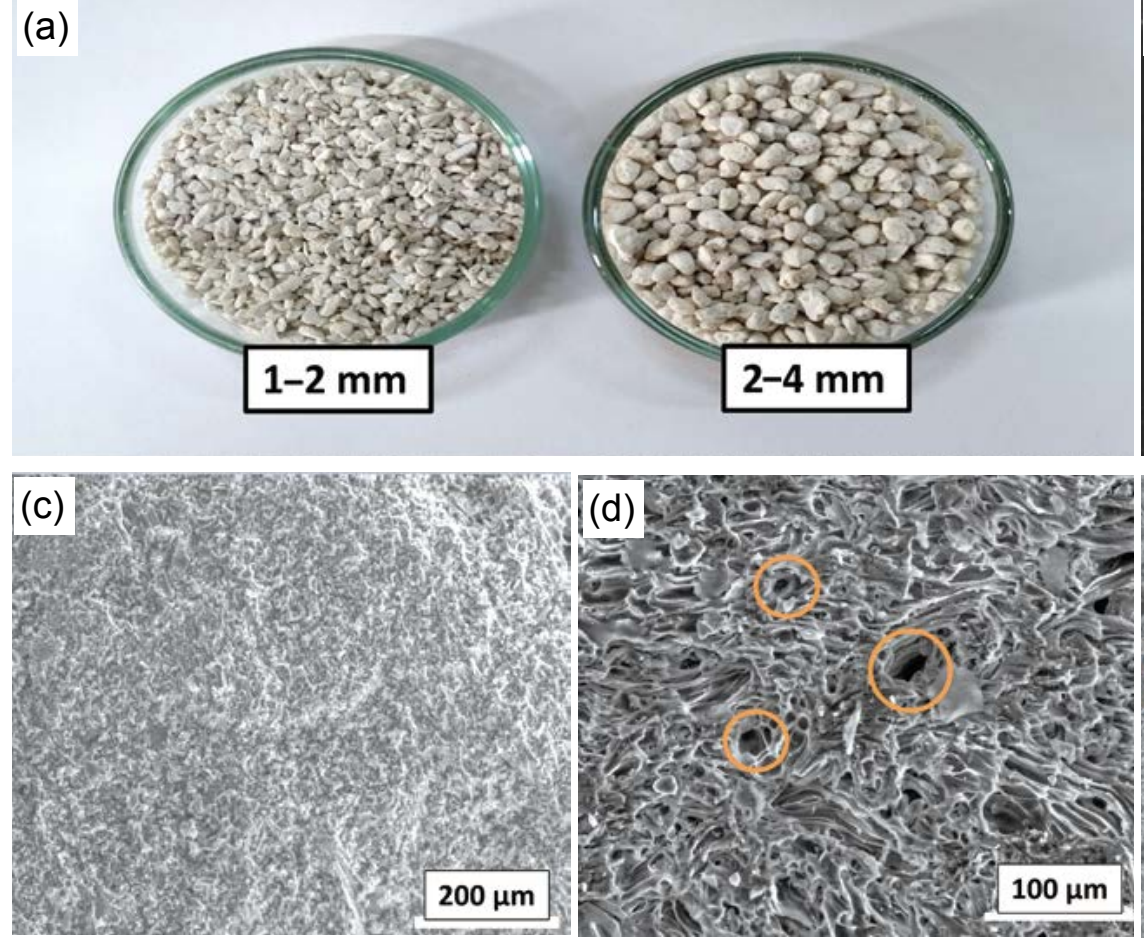

Fig. 1: Macro (a) and SEM images of pumice particles: circular and tubular surface gaps enclosed with orange circles (b), solid textured zone (c), circular micropores depicted in small circles (d), and local high porosity zone indicated in dashed circle (e)

Many micropores present in both the outer surface and inner structure of the particles [Fig. 1(d)], and porosity gradient can be seen in certain zones due to the natural formation of the pumice [Fig. 1(e)]. Figure 2 depicts the specially designed casting machine.

An induction furnace (Sotec F10 Induction Furnace, max. $1,100{ }^{\circ} \mathrm{C}$ capacity) was used to melt the matrix metal. Pumice particles were added to the die cavity after preheated to $200{ }^{\circ} \mathrm{C}$ by an electric resistance furnace (Protherm PLF 110/6, max. $1,100{ }^{\circ} \mathrm{C}$ capacity). Then, the die was sealed with a steel top lid, and the liquid aluminum

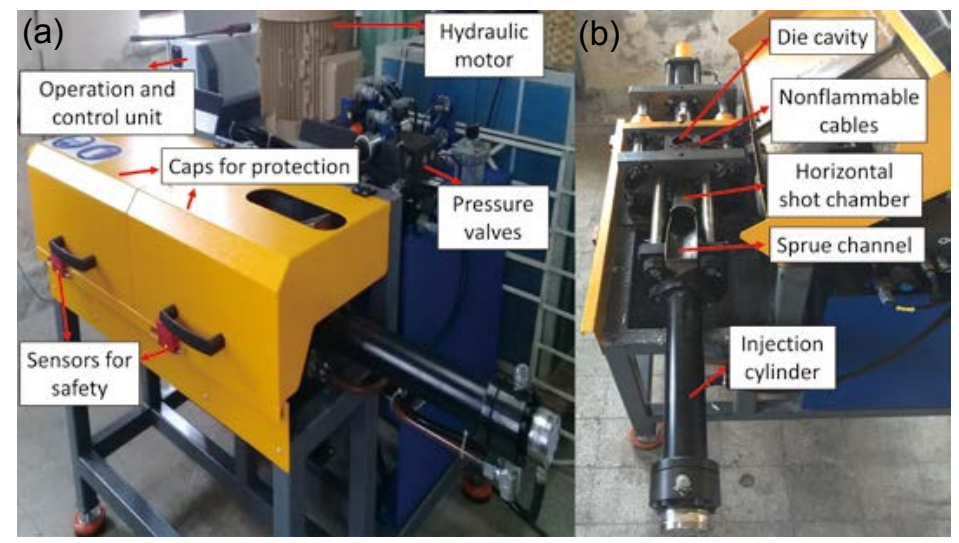

Fig. 2: Specially designed casting machine: system components (a) and injection line (b) $\left(800{ }^{\circ} \mathrm{C}\right)$ was poured using a graphite crucible with an inclined sprue. Finally, infiltration pressure was applied automatically with a steel plunger moving horizontally.

All samples ( $80 \mathrm{~mm}$ in height and $45 \mathrm{~mm}$ in diameter) were categorized based on their density values. Half of the samples were solution treated at $480{ }^{\circ} \mathrm{C}$ for $3 \mathrm{~h}$ and aging at $120^{\circ} \mathrm{C}$ for $24 \mathrm{~h}$.

Microstructural observations were conducted using SEM (Fei Quanta FEG 250). Before the micro characterization, related foam surfaces were subject to grinding (with $\mathrm{SiC}$ emery papers from 180 grid to 1,200 grid), polishing (with Metkon Diapat diamond suspension), and ultrasonic cleaning.

To determine the mechanical properties of fabricated foams, quasi-static compression tests were performed by utilizing the Dartec $600 \mathrm{kN}$ uniaxial testing equipment. In advance of the loading, the top and bottom surfaces of the syntactic samples were machined precisely via a face-turning installment in order to create sufficient parallelism between the loading platens. All force and displacement data were collected with MTS Flex Test 40 and TW Elite data acquisition software programs and were converted to engineering stress and strain values using initial cross-sectional area and sample height 
information. Compressive strength $\left(\delta_{\text {cmp }}\right)$, plateau stress $\left(\delta_{\mathrm{pl}}\right)$, energy absorption $(W)$, and densification strain $\left(e_{\text {ple }}\right)$ values were determined by using ISO 13314 standard $^{[39]}$.

\section{Results and discussion}

\subsection{Physical properties}

In Fig. 3, three different product groups can be seen in detail. It can be seen that there are no surface defects, cracks, or oxide spots on the fabricated samples. In addition, there are no shrinkage cavities and casting voids on the outer surface of the foams. The sample densities vary between 1.50 and $1.80 \mathrm{~g} \cdot \mathrm{cm}^{-3}$, as shown in Table 3. Considering that foam densities obtained via conventional methods are between $1-2 \mathrm{~g} \cdot \mathrm{cm}^{-3}$, this range can be interpreted as mid-level compared to other metal syntactics reported in the literature ${ }^{[2-3]}$.

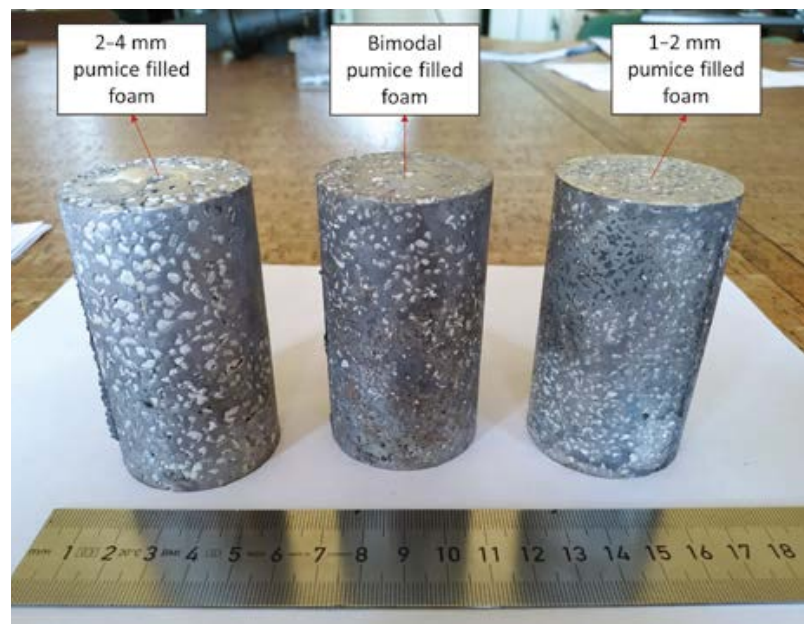

Fig. 3: Fabricated foam samples with different sizes of reinforced pumice particles

Table 3: Average values of the physical features for each group of samples

\begin{tabular}{|c|c|c|c|c|c|c|c|}
\hline Status & $\begin{array}{l}\text { Mass } \\
(\mathrm{g})\end{array}$ & $\begin{array}{l}\text { Diameter } \\
\text { (mm) }\end{array}$ & $\begin{array}{l}\text { Height } \\
\text { (mm) }\end{array}$ & $\begin{array}{l}\text { Density } \\
\left(\mathrm{g} \cdot \mathrm{cm}^{-3}\right)\end{array}$ & Filler size & $\begin{array}{l}\text { Filler volume } \\
\text { (vol.\%) }\end{array}$ & $\begin{array}{c}\text { Porosity } \\
(\%)\end{array}$ \\
\hline As-cast & 219.01 & 44.55 & 77.93 & 1.80 & $1-2 \mathrm{~mm}$ & 48.72 & 34.28 \\
\hline Heat treated & 218.27 & 44.48 & 77.90 & 1.80 & $1-2 \mathrm{~mm}$ & 48.77 & 34.35 \\
\hline As-cast & 196.53 & 44.40 & 77.51 & 1.63 & Bimodal & 55.55 & 40.14 \\
\hline Heat treated & 197.43 & 44.60 & 77.15 & 1.63 & Bimodal & 55.50 & 40.11 \\
\hline As-cast & 182.58 & 44.47 & 77.88 & 1.50 & $2-4 \mathrm{~mm}$ & 59.74 & 44.68 \\
\hline Heat treated & 185.04 & 44.24 & 78.14 & 1.53 & $2-4 \mathrm{~mm}$ & 58.73 & 43.62 \\
\hline
\end{tabular}

As proclaimed in the previous MMSF efforts ${ }^{[37,38]}$, the porosity values of the foam samples were calculated by using the equations given below:

$$
\begin{gathered}
F_{\mathrm{fil}}=\left(\frac{V_{\mathrm{syn}}-\left(\frac{m_{\mathrm{syn}}-m_{\mathrm{fil}}}{\rho_{\mathrm{alu}}}\right)}{V_{\mathrm{syn}}}\right) \times 100 \\
\rho_{\mathrm{fil}}=\frac{m_{\mathrm{fil}}}{V_{\mathrm{syn}}-\left(\frac{m_{\mathrm{syn}}-m_{\mathrm{fil}}}{\rho_{\mathrm{alu}}}\right)} \\
F_{\mathrm{TP}}=F_{\mathrm{fil}}\left(1-\frac{\rho_{\mathrm{fil}}}{\rho_{\mathrm{sd}}}\right)
\end{gathered}
$$

where $F_{\text {fil }}$ is the volume fraction of filler material, $m_{\text {syn }}$ is the foam mass, $\rho_{\text {fil }}$ is the particle density of pumice particles (it varies between 0.77 and 0.62 depending on the particle size), $F_{\mathrm{TP}}$ is the total foam porosity, $V_{\text {syn }}$ is the volume of the syntactic sample, $m_{\mathrm{fil}}$ (44 $\mathrm{g}$ for small sized particles, $46.6 \mathrm{~g}$ for bimodal particles and $45.7 \mathrm{~g}$ for big sized particles) is the mass of filler material, $\rho_{\text {alu }}\left(2.81 \mathrm{~g} \cdot \mathrm{cm}^{-3}\right)$ is matrix density for Al7075 alloy and $\rho_{\text {sd }}(2.5$ $\left.\mathrm{g} \cdot \mathrm{cm}^{-3}\right)$ is density of solid part of the filler.

From Table 3, the highest average porosity value of $44.68 \%$ belongs to 2-4 $\mathrm{mm}$ pumice filled sample while the lowest average value is $34.28 \%$ for $1-2 \mathrm{~mm}$ pumice filled sample. Besides, as for bimodal samples, the average porosity is $40.12 \%$.
This can be attributed to the packing conditions in the die cavity that affect the filler breakage during the application of infiltration pressure. In the 1-2 mm small-sized pumice filled samples, filler breakage tendency is higher due to the high stacking ratio and this is also the reason for the high-density levels. However, that case is quite opposite for 2-4 mm big-sized pumice filled samples and leads to low density levels. In addition, thanks to bimodality, high stacking ratio of the small-sized particles can be decreased and moderate level density/porosity values can be attained.

\subsection{Microstructure}

According to previous studies ${ }^{[2,3,12,26]}$, there are some different inner structures in a metallic syntactic foam: perfect infiltration zones, particle merging points, casting voids, broken particles, and interface zones. In this research, all of these structures were observed in the fabricated foams. Figure 4 depicts SEM images of the fabricated foam samples. Figure 4(a) proves the feasibility of the cold chamber die casting on MMSFs owing to infiltration capacity in the narrow gaps. In addition, in some cases shown in Fig. 4(b), molten metal can penetrate into the pores due to the process pressure, and this causes increase of density. A similar metal filling is seen more apparently in the studies focusing on thin-walled hollow spheres ${ }^{[3,5,12]}$. As a consequence of defects forming in long transportation efforts and infiltration 

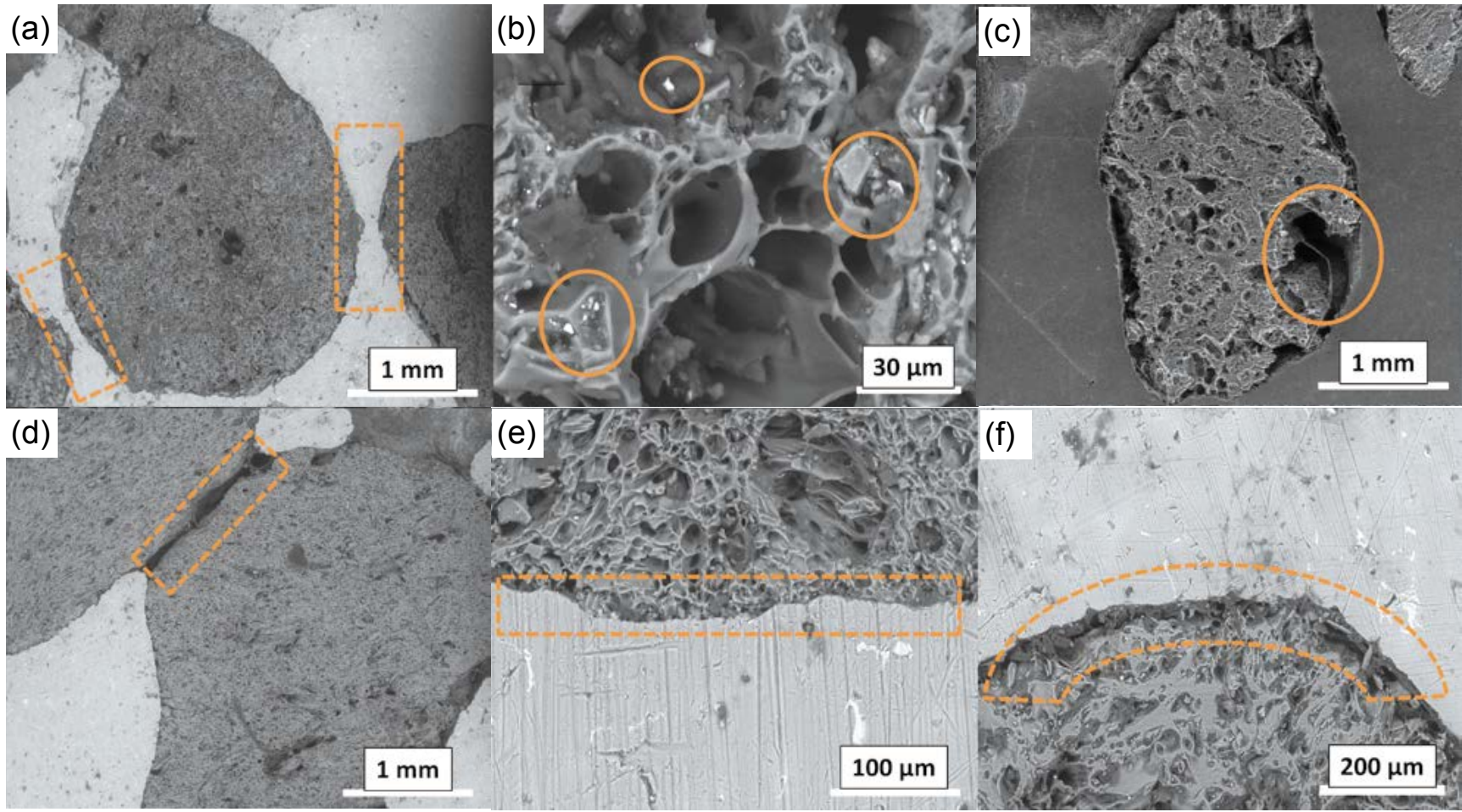

Fig. 4: SEM images of fabricated foams: infiltration in narrow gaps (a), matrix penetration into the filler (b), filler breakage (c), partial sintering of filler particles (d), good metal flow in a flat line (e), and good wettability on filler edges (f)

pressure, some filler particles might be broken apart [Fig. 4(c)]. Also, Fig. 4(d) shows that pumice particles display a merging tendency nearby their first contact points depending on their preheating and packing circumstances. Pumice is a randomly shaped material and this feature might result in infiltration challenges but the offered technique in this study can overcome this by providing multi-directional penetration between the reinforcement particles. At this point, flawless flat metal flowing, and good wettability on the filler edges can be noticed in Fig. 4(e) and Fig. 4(f).

\subsection{Mechanical properties}

Table 4 and Fig. 5 show the compressive properties and stress/ strain curves of the fabricated foams, respectively.

Compressive strength values of the fabricated foams were determined using the offset stress of $0.1 \%$ deformation, so this term is also named $0.1 \%$ proof stress in some other works ${ }^{[18,37]}$. It can be deduced from Fig. 5 and Table 4 that as particle size becomes bigger, compressive strength $\left(\delta_{\text {cmp }}\right)$ values of the foam samples show decreasing trend because of density diminishment. This situation can be attributed to the increasing volume fraction of load-bearing metal matrix and similar results were also reported by other researchers ${ }^{[18,38]}$. This trend is also valid for heat-treated foams [Fig. 6(a)]. Additionally, comparison with the as-cast samples shows that heat treatment has a positive influence on the compressive strength values for all the three product groups. While the highest compressive strength value of $96.24 \mathrm{MPa}$ belongs to the heat-treated sample of SF4, the lowest value of $21.12 \mathrm{MPa}$ belongs to the as-cast sample of SF14. Compared with big-sized and small-sized pumice reinforced samples, bimodal samples have a moderate level of results (46.13 MPa and 71.28 MPa in average for ascast and heat-treated samples, respectively).

Plateau stress $\left(\delta_{\mathrm{pl}}\right)$ is defined as the mean stress between $20 \%$ and $40 \%$ deformation region. This region is a characteristic zone that has an important impact on the energy absorption behaviors and damage modes of the MMSFs. Typically, there are certain plateau behaviors ${ }^{[3,9,30]}$ depending on matrix/ filler matchings: flat line (ideal theoretical state), fluctuating line, decremental curve, and rising trend. As shown in Fig. 5, mixed-type plateau behaviors are observed with the effects of particle size and bimodality. Furthermore, Fig. 5 indicates that heat-treated samples exhibit superior plateau stress values regardless of particle size and bimodality. In addition, as long as the particle size increases, the average plateau stress of the foam samples decreases in connection with diminishing density and increasing porosity [Fig. 6(b)]. Table 4 shows that the maximum plateau stress value of $47.75 \mathrm{MPa}$ is calculated for heat-treated sample of SF6 whereas the minimum value of $12.16 \mathrm{MPa}$ is determined for the as-cast sample of SF15. Compared with big-sized and small-sized pumice reinforced samples, bimodal samples show an intermediate level of plateau stress (19.82 $\mathrm{MPa}$ and $29.95 \mathrm{MPa}$ in average for ascast and heat-treated samples, respectively).

Energy absorption $(W)$ values of the fabricated foam samples were obtained by calculating the area under the stress-strain curve up to $50 \%$ deformation point according to ISO 13314 standard. Therefore, it can be propounded that the first peak stress level to $20 \%$ deformation and the plateau behavior are 
Table 4: Compressive properties of fabricated foams

\begin{tabular}{|c|c|c|c|c|c|c|}
\hline Sample code & Particle size & State & $\delta_{\mathrm{cmp}}(\mathrm{MPa})$ & $\delta_{p l}(\mathrm{MPa})$ & $W\left(M J \cdot m^{-3}\right)$ & $e_{\text {ple }}(-)$ \\
\hline SF1 & \multirow{6}{*}{$1-2 \mathrm{~mm}$} & \multirow{4}{*}{ As-cast } & 57.86 & 27.89 & 17.86 & 0.68 \\
\hline SF2 & & & 73.11 & 27.06 & 18.02 & 0.52 \\
\hline SF3 & & & 66.87 & 25.9 & 16.44 & 0.51 \\
\hline SF4 & & & 96.24 & 47.38 & 31.34 & 0.67 \\
\hline SF5 & & \multirow[t]{2}{*}{ Heat-treated } & 80.29 & 24.29 & 20.32 & 0.7 \\
\hline SF6 & & & 83.74 & 47.75 & 28.19 & 0.61 \\
\hline SF7 & \multirow{6}{*}{ Bimodal } & \multirow{4}{*}{ As-cast } & 44.56 & 25.23 & 14.05 & 0.67 \\
\hline SF8 & & & 48.77 & 13.65 & 13.16 & 0.47 \\
\hline SF9 & & & 45.06 & 20.59 & 12.59 & 0.64 \\
\hline SF10 & & & 70.39 & 34.54 & 21.16 & 0.71 \\
\hline SF11 & & \multirow[t]{2}{*}{ Heat-treated } & 76.33 & 22.95 & 22.62 & 0.68 \\
\hline SF12 & & & 67.13 & 32.37 & 20.11 & 0.54 \\
\hline SF13 & \multirow{6}{*}{$2-4 \mathrm{~mm}$} & \multirow{4}{*}{ As-cast } & 26.73 & 19.08 & 9.81 & 0.62 \\
\hline SF14 & & & 21.12 & 17.46 & 8.35 & 0.56 \\
\hline SF15 & & & 30.43 & 12.16 & 8.97 & 0.66 \\
\hline SF16 & & & 45.39 & 21.97 & 13.61 & 0.42 \\
\hline SF17 & & \multirow[t]{2}{*}{ Heat-treated } & 49.42 & 34.67 & 15.09 & 0.62 \\
\hline SF18 & & & 45.87 & 21.94 & 13.07 & 0.69 \\
\hline
\end{tabular}
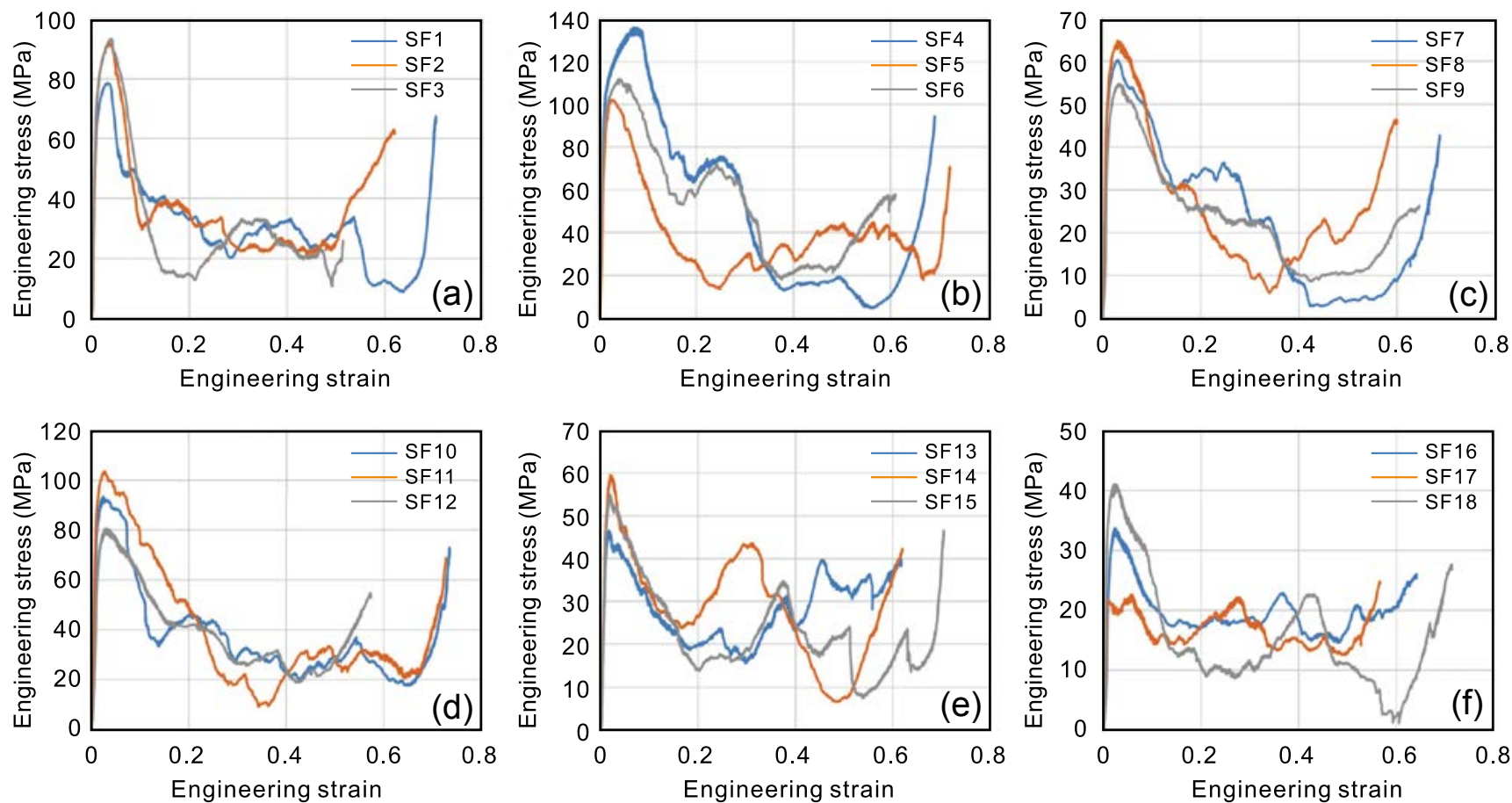

Fig. 5: Engineering stress-strain curves of fabricated syntactic foams: as-cast 1-2 $\mathrm{mm}$ pumice filled (a), heattreated 1-2 mm pumice filled (b), as-cast bimodal (c), heat-treated bimodal (d), as-cast 2-4 mm pumice filled (e) and heat-treated 2-4 $\mathrm{mm}$ pumice filled (f) 

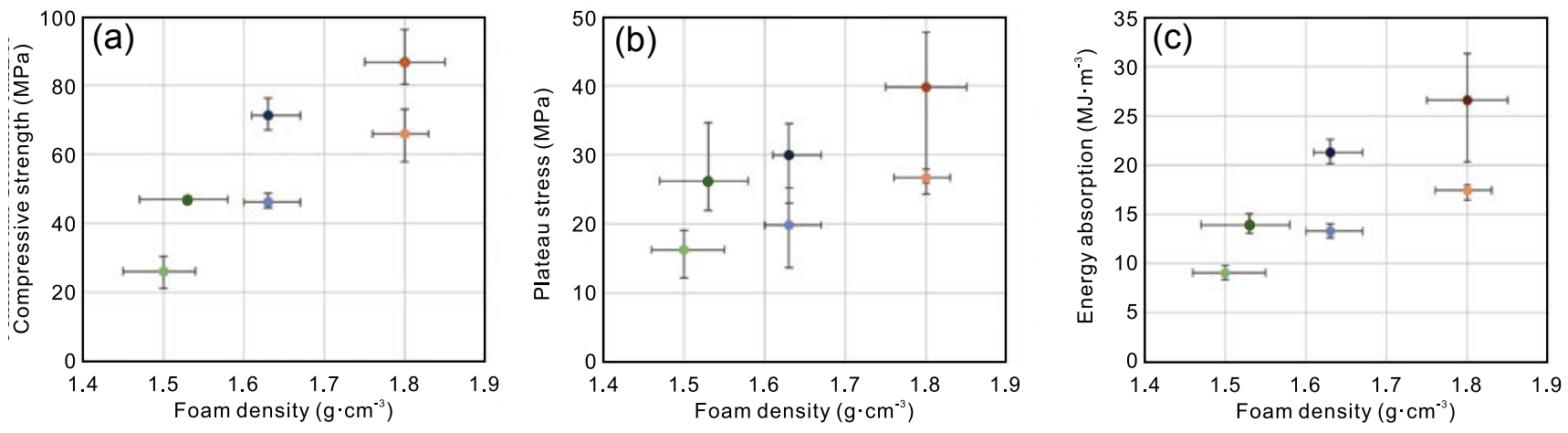

$\begin{array}{lll}-1-2 \mathrm{~mm} \text { as-cast } & - \text { Bimodal as-cast } & -2-4 \mathrm{~mm} \text { as-cast } \\ -1-2 \mathrm{~mm} \text { heat-treated } & - \text { Bimodal heat-treated } & \bullet 2-4 \mathrm{~mm} \text { heat-treated }\end{array}$

Fig. 6: Relationship between mechanical properties and foam density values in terms of compressive strength (a), plateau stress (b) and energy absorption (c)

determinant factors for higher energy absorption levels. From Table 4 and Fig. 6(c), it can be emphasized that small-sized particles and heat treatment improve the energy absorption capability of the foam samples. Similar to the findings shared in this study, some other research groups working on MMSFs also revealed the affirmative relationship between the heat treatment and energy absorption capacity ${ }^{[15,18,25,37]}$. According to the collected data in the compression tests, the highest value of $31.34 \mathrm{MJ} \cdot \mathrm{m}^{-3}$ and the lowest value of $8.35 \mathrm{MJ} \cdot \mathrm{m}^{-3}$ belong to the heat-treated SF4 and as-cast SF14. As for bimodal foams, their energy absorption performance can also be assessed as mid-level since these samples have medium levels of porosity and density.

The last stage of the compressive deformation is known as the densification zone, and the measured loading force goes up sharply in this stage because of decreasing sample height and compacted structure of extremely damaged test sample. According to the related standard, densification begins at the strain point where the plateau region ends and this point is called plateau-end-point or densification strain. Plateau-end-point $\left(e_{\text {ple }}\right)$ is a strain value corresponding to a stress value that is 1.3 times of plateau stress. It can be seen from Table 4, considering the particle size effect, bimodality, and heat treatment conditions, there is not any noteworthy difference between the plateau-endpoint values. This situation can be explained by the complex pore structure of pumice particles and different particle distribution in each foam body leading to a density gradient. When all samples are compared to each other in terms of densification behaviors, it is seen that the longest plateau region is for heat-treated bimodal sample of SF10 with 0.71 plateau-end-point. However, the shortest plateau area is for heat-treated 2-4 mm pumice filled sample of SF16 with 0.42 strain value.

\subsection{Failure characteristics}

Generally, failure modes of the MMSFs are divided into two types: ductile barreling deformation and brittle fracture with apparent cracks ${ }^{[2,3,26,40]}$. In addition to these modes, mixed type deformation styles that might be ductile dominant or brittle dominant are also observed depending upon matrix/filler matching, fabrication procedures, pore nature of filler material, ductility of the matrix alloy, and heat treatment state of the matrix. There are also some different mixed type failure styles reported in the literature ${ }^{[18,30,37,41]}$ : top barreling deformation with surface cracks, bottom barreling deformation with surface cracks, middle barreling deformation with surface cracks, x-type surface cracks with low barreling effect, v-type surface cracks with low barreling effects, only $45^{\circ}$ body crack with low barreling effect.

Figure 7 demonstrates damage stages of the as-cast samples of three different product groups in view of increasing deformation percentages. From Fig. 7, it is obvious that all samples deform elastically initially and display low barreling at $10 \%$ deformation without any surface cracks. At $20 \%$ deformation, nearly $45^{\circ}$ surface cracks are detected in the main body of bimodal sample and this is also responsible for the declining trend of engineering stress values depicted in Fig. 5(c). However, 2-4 $\mathrm{mm}$ and 1-2 $\mathrm{mm}$ pumice filled samples continue low barreling deformation, might be due to their better matrix/ filler harmony and fewer contact/sintering points between filler particles. When the deformation reaches $30 \%$, Fig. 7 shows that all samples experience mixed type deformation with different sized and oriented cracks but none of them loses their monolithic structure. At this stage of deformation, pumice particles located at the shear plane of the foam body are extremely damaged and pulverized. At $40 \%$ deformation, reverse v-type crack and x-type body crack become more visible for 1-2 mm and 2-4 mm pumice filled samples, respectively. The $50 \%$ deformation is the last point for the energy abruption calculations and usually the densification region at this point is used for MMSFs. In this investigation, all samples are damaged majorly at 50\% deformation and break into small parts, then densification begins with further loading.

To understand the deformation systematically, afterdeformation states of the compressed as-cast foam samples are shown in Fig. 8. Figure 8(a) shows that the top surfaces of the as-cast foams remain intact due to continuous contact with the surface of the test plate. The low deformation zones (LDZ) 

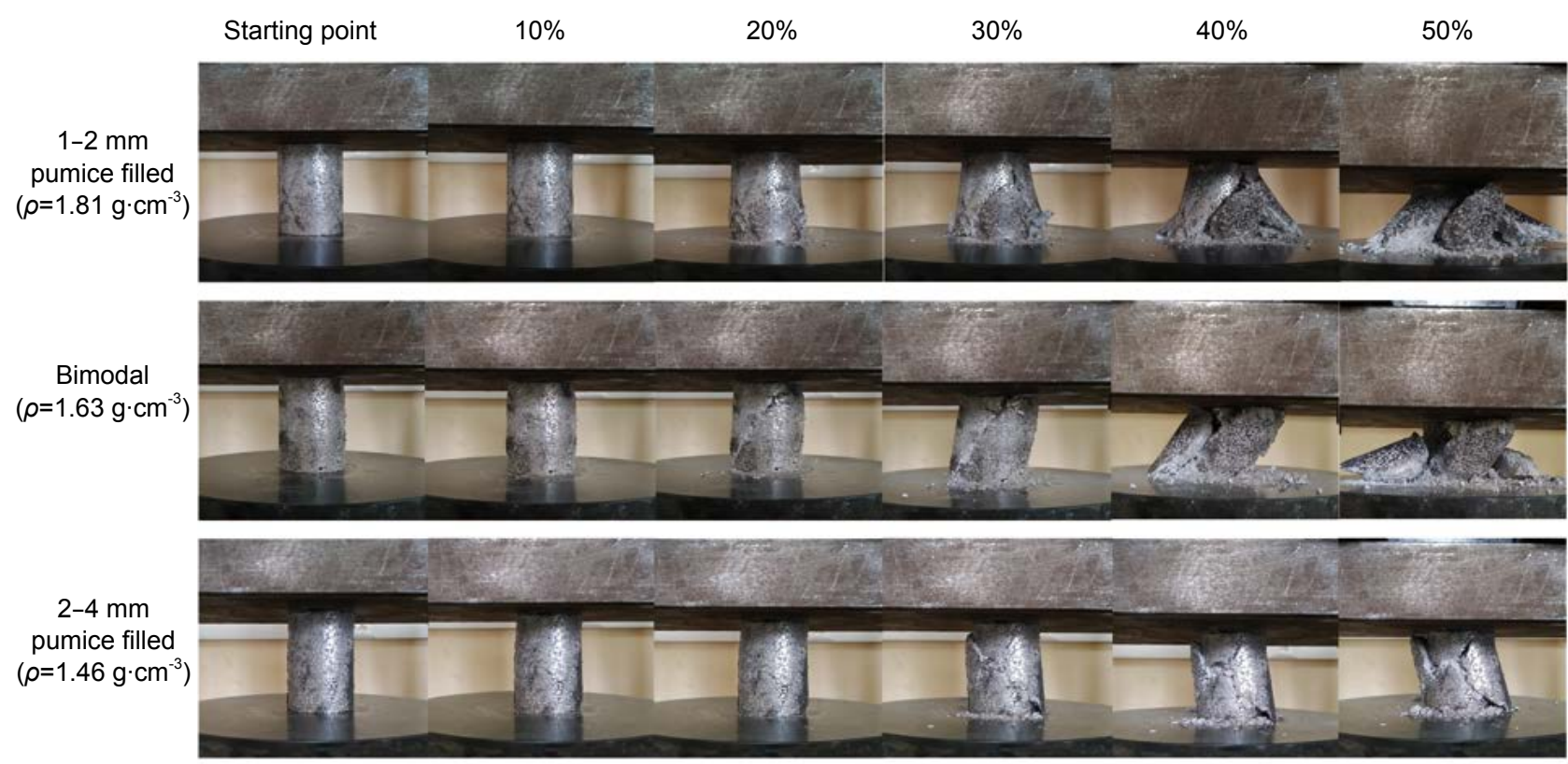

Fig. 7: Deformation stages of as-cast foam samples

(a)

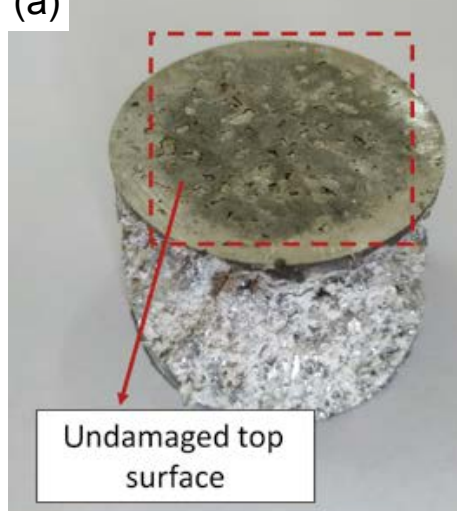

(c)

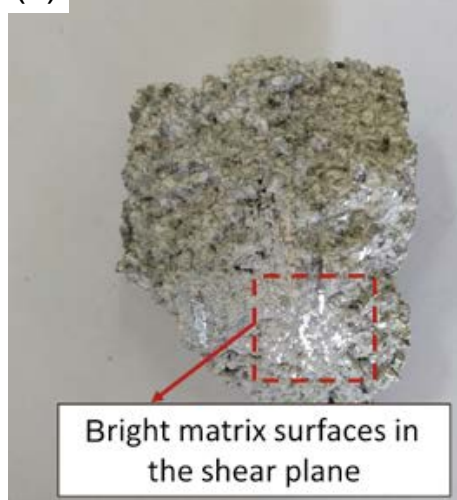

(b)

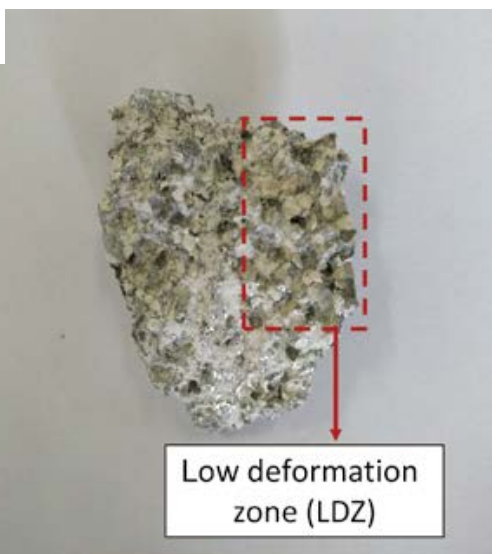

(d)

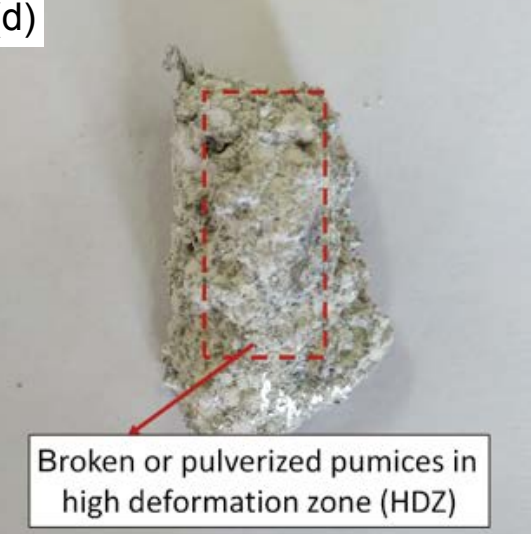

Fig. 8: After-deformation images of compressed as-cast samples: top surface (a), low deformation zone (b), shear zone (c) and high deformation zone (d)

resulting from density gradient of the foam body and the high deformation zones (HDZ) having pulverized filler particles are shown in Fig. 8(b) and Fig. 8(d), respectively. Besides, in Fig. 8(c), bright matrix surface can be seen in the shear plane. In addition, in Fig. 9(a) and Fig. 9(b), undeformed pumice particles with intact cell struts in the LDZ and severe-damaged fragments in the HDZ can be distinguished in micro-scale.
In Fig. 10, failure styles of the heat-treated syntactic foam samples can be analyzed and compared with their as-cast versions to scrutinize the differences. At the initial stages of the deformation, although all heat-treated samples have higher yield points, they behave similarly to the as-cast ones and deform elastically. Nevertheless, it can be found from Fig. 10 that all samples begin to rupture due to distinct surface cracks 


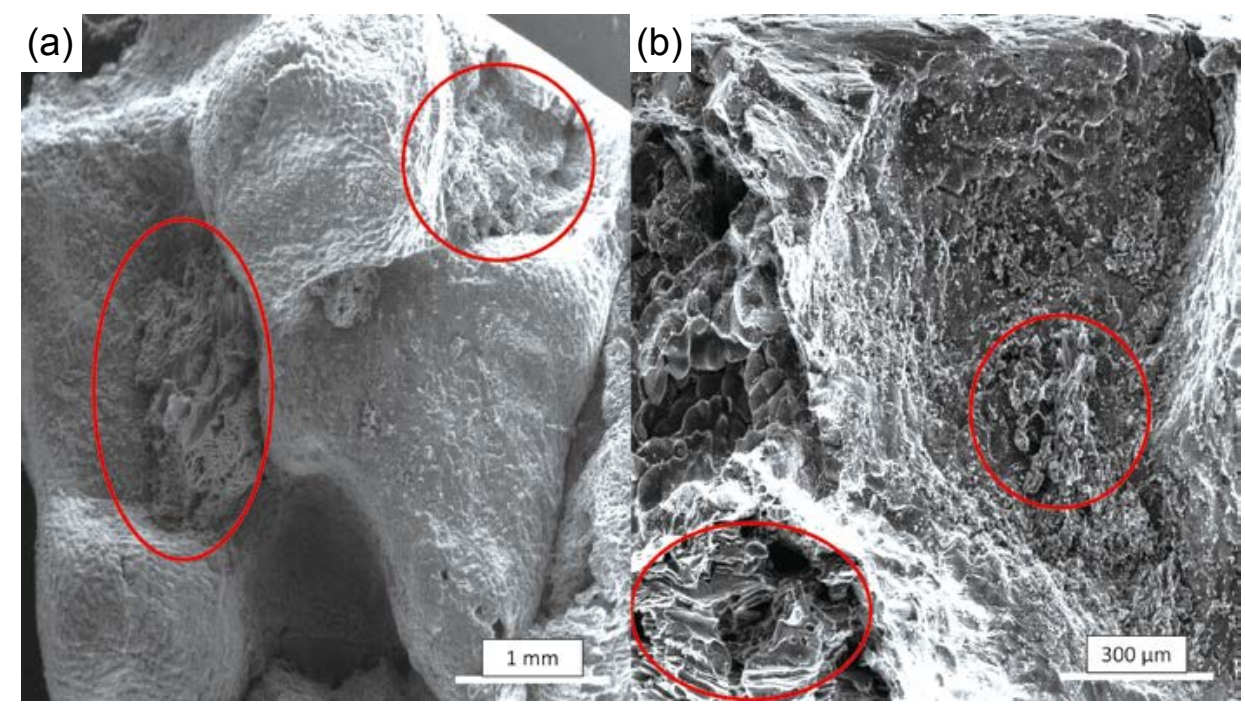

Fig. 9: SEM views of damaged surfaces of as-cast samples: undamaged pumice particles in LDZ (a) and fragments of damaged pumice particles in HDZ (b)
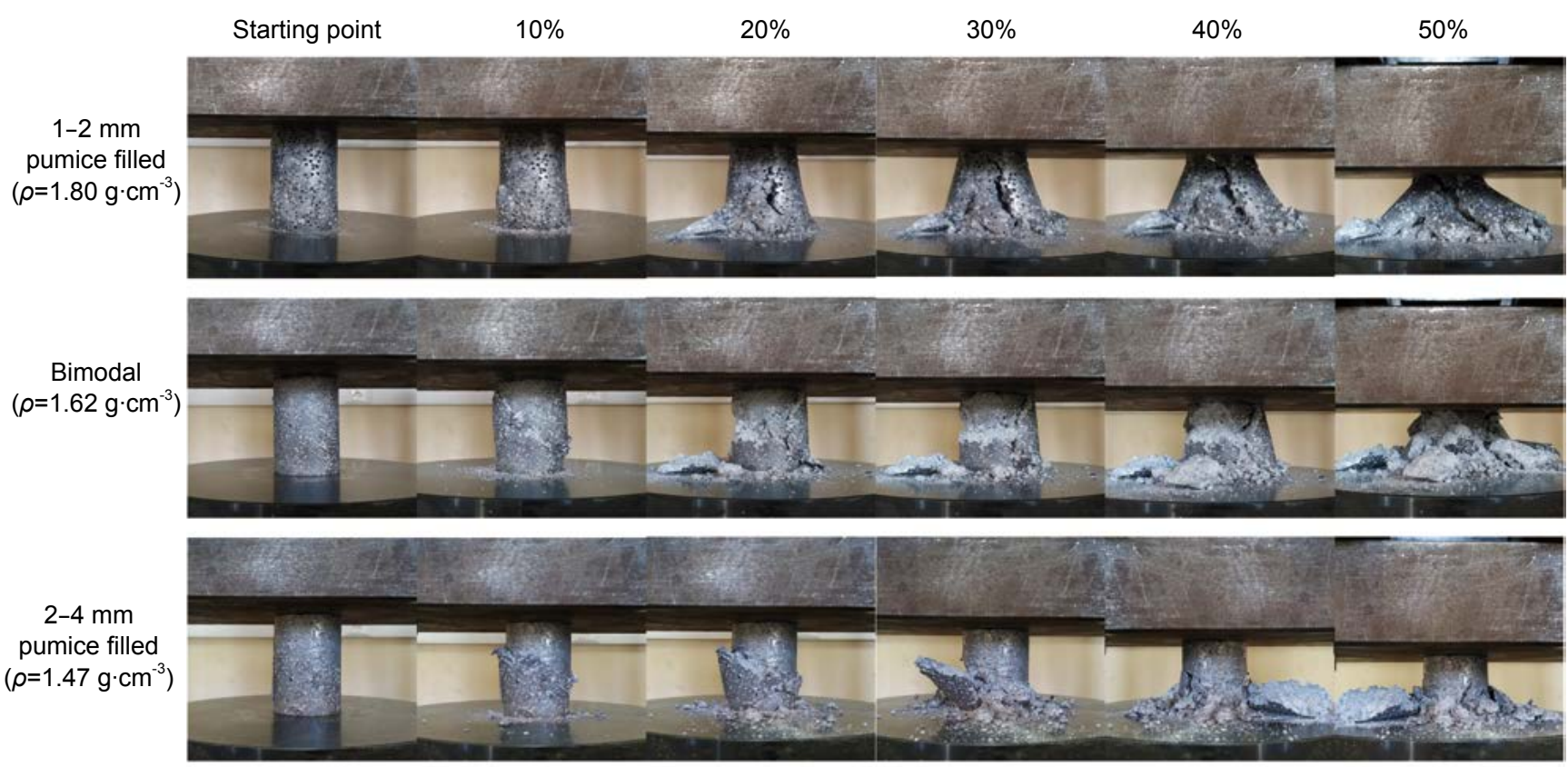

Fig. 10: Deformation stages of heat-treated foam samples

at $10 \%$ deformation despite of the particle size. This case can be counted as a significant difference compared to the as-cast foams exhibiting ductile barreling without any surface cracks at the same deformation level. All types of foam samples, when the deformation is $20 \%$, lose their monolithic structure. This observation is another characteristic difference for the heat-treated samples and can be explained with their rising brittleness/diminishing fracture toughness features. At $30 \%$ deformation, as the body cracks of the samples get deeper and longer, the main deformation concentrates on the shear planes, barreling effect is seen at the bottom of the samples and unharmed zones (death zones) emerge in which almost all pumice particles remain undeformed, which are related to the existence of density gradient in the foam body. Similiar findings were also pointed out by other researchers ${ }^{[38,42]}$. As of
$40 \%$ deformation, the monolithic structures of the samples are deteriorated and some big-sized fragments separate completely from the main foam body with lots of small-sized fragments. While the heat-treated 1-2 mm pumice filled sample displays a similar style with its as-cast version from the point of crack propagation route, bimodal and $2-4 \mathrm{~mm}$ pumice filled samples differ from their as-cast versions in the aspects of crack propagation ways. This result might be explicated with the mechanical anisotropy of the pumice particles ${ }^{[43]}$. Afterdeformation images of the heat-treated samples can be seen in Fig. 11. Different from the as-cast samples, the top surfaces of the heat-treated samples show lots of cracking marks [Fig. 11(a)], and major inner cracks are present in the separated fragments as a consequence of ascending matrix brittleness [Fig. 11(b)]. Moreover, similar to the situation observed for as- 
(a)

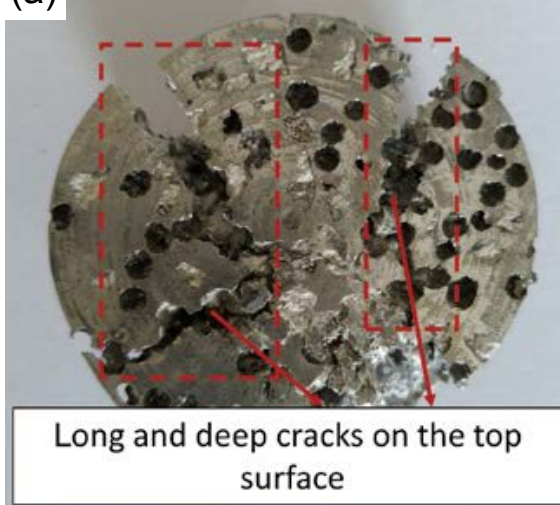

(c)

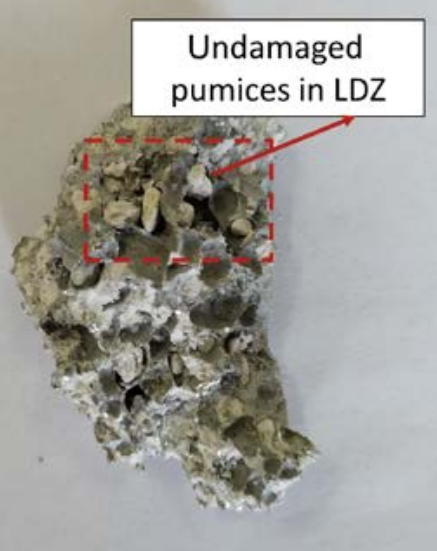

(b)

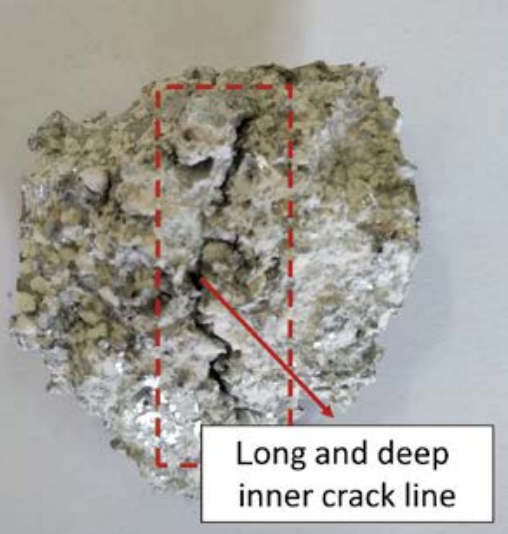

(d)

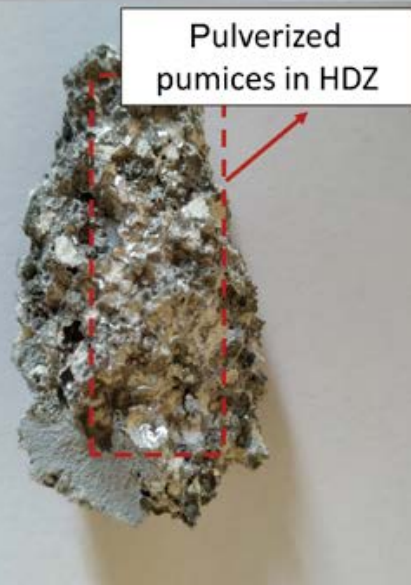

Fig. 11: After-deformation images of compressed heat-treated samples: top surface (a); major inner crack line (b); low deformation zone (c); and high deformation zone (d)

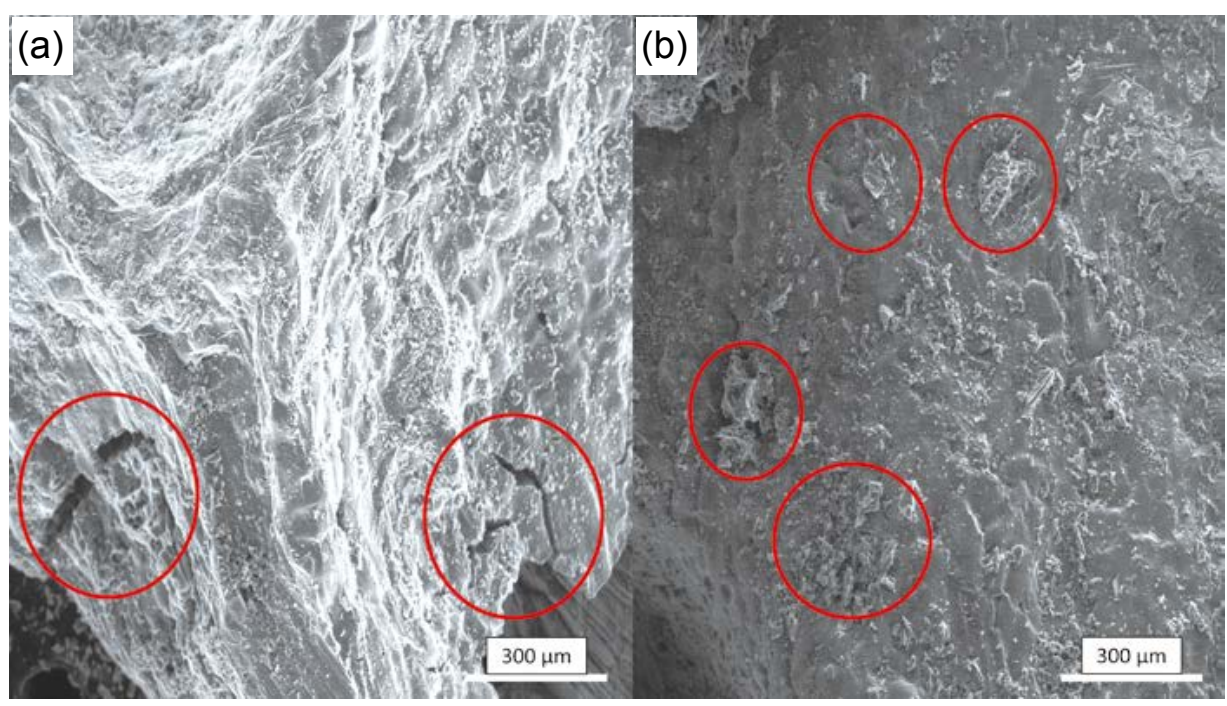

Fig. 12: SEM images of damaged heat-treated samples: micro-cracks (a) and pumice sediments in high deformation zone (b)

cast samples, low and high deformation zones exist also in the damaged fragments of heat-treated samples [Fig. 11(c) and Fig. 11(d)]. Apart from the macro evidence, Fig. 12(a) and Fig. 12(b) demonstrate the inner secondary micro-cracks formed in the metal matrix, and micro sediments located in the inner cavity appearing after pulverized the pumice particles.

\section{Conclusions}

In the light of fabrication procedure, physical and microstructural properties, mechanical responses, and failure characteristics of the manufactured pumice filled AA7075 syntactic foams, the following conclusions can be made:

(1) Due to its highly porous structure, low-cost and natural- 
based pumice can be used in syntactic foam applications as an alternative filler material to the expensive thin-walled hollow spheres.

(2) AA7075 metallic syntactic foams reinforced with 1-2 mm, 2-4 mm, and bimodal (50vol.\%) pumice particles can be manufactured via industrial-focused cold chamber die casting technology. In comparison with other lab-scaled techniques, the proposed method is highly promising on the road to probable applications.

(3) As the pumice particle size increases, total porosity values of the fabricated foams increase due to the high-volume fraction of undamaged reinforced particles during the application of the infiltration pressure. Besides, with the bimodality, mid-level density and porosity results can be obtained.

(4) Microstructural analysis indicates that effective infiltration can be observed via the offered die casting method even in micron-scaled very narrow gaps between the pumice particles.

(5) As the particle size increases, the average compressive strength, plateau stress and energy absorption capabilities of the fabricated foams decreases owing to density dimimishment in the samples.

(6) Heat treatment has a positive influence on the mechanical properties of the fabricated foams independently of bimodality and particle size.

(7) Because of the complex pore structure, mechanical anisotropy and aspherical outer geometry of the pumice, mixed type damage characteristic emerges for both the as-cast and heat-treated foam samples. Heat-treated samples exhibit brittle dominant mixed type deformation and early body cracks can easily be seen in the foam samples. However, for the as-cast samples, the ductile mechanism is dominant at the first half of the deformation, and the brittle mechanism becomes more influential at the second half of the deformation.

\section{Acknowledgement}

We would like to thank the micro characterization unit at Innovative Technologies and Application Research Center (YETEM), Suleyman Demirel University, Isparta, Turkey.

\section{References}

[1] Gupta N, Zeltmann S E, Shunmugasamy V C, et al. Applications of polymer matrix syntactic foams. The Journal of the Minerals, Metals \& Materials Society, 2014, 66(2): 245-254.

[2] Orbulov I N, Szlancsik A. On the mechanical properties of aluminum matrix syntactic foams. Advanced Engineering Materials, 2018, 20(5): 1700980.

[3] Bolat Ç, Akgün I, Gökşenli A. On the way to real applications: Aluminum matrix syntactic foams. European Mechanical Science, 2020, 4(3): 131-141.

[4] Meng J, Liu T W, Wang H Y, et al. Ultra-high energy absorption high-entropy alloy syntactic foam. Composites Part B: Engineering, 2021, 207(2): 108563.

[5] Yang Q, Cheng J, Wei Y, et al. Innovative compound casting technology and mechanical properties of steel matrix syntactic foams. Journal of Alloys and Compounds, 2021, 853: 156572.
[6] Szlancsik A, Katona B, Kemény A, et al. On the filler materials of metal matrix syntactic foams. Materials, 2019, 12(12): 2023.

[7] Anbuchezhiyan G, Mohan B, Sathianarayanan D, et al. Synthesis and characterization of hollow glass microspheres reinforced magnesium alloy matrix syntactic foam. Journal of Alloys and Compounds, 2017, 719: 125-132.

[8] Lehmhus D, Weise J, Szlancsik A, et al. Fracture toughness of hollow glass microsphere-filled iron matrix syntactic foams. Materials, 2020, 13(11): 2566. doi:10.3390/ma13112566.

[9] Fiedler T, Al-Sahlani K, Linul P A, et al. Mechanical properties of A356 and ZA27 metallic syntactic foams at cryogenic temperature. Journal of Alloys and Compounds, 2019: 152181.

[10] Anbuchezhiyan G, Muthuramalingam T, Mohan B. Effect of process parameters on mechanical properties of hollow glass microsphere reinforced magnesium alloy syntactic foams under vacuum die casting. Archives of Civil and Mechanical Engineering, 2018, 18(4): 1645-1650.

[11] Mondal D P, Datta Majumder J, Jha N, et al. Titaniumcenosphere syntactic foam made through powder metallurgy route. Materials \& Design, 2012, 34: 82-89.

[12] Su M M, Wang $H$, Hao H. Compressive properties of aluminum matrix syntactic foams prepared by stir casting method. Advanced Engineering Materials, 2019: 900183. doi:10.1002/ adem.201900183.

[13] Katona B, Orbulov I N. Periodica Polytechnica Mechanical Engineering, 2017, 61(2): 146-152.

[14] Cox J, Luong D D, Shunmugasamy V, et al. Dynamic and thermal properties of aluminum alloy A356/silicon carbide hollow particle syntactic foams. Metals, 2014, 4(4): 530-548.

[15] Pan L W, Yang Y, Ahsan M U, et al. Zn-matrix syntactic foams: Effect of heat treatment on microstructure and compressive properties. Materials Science and Engineering: A, 2018, 731: 413-422.

[16] Goel M D, Parameswaran V, Mondal D P. High strain rate response of cenosphere-filled aluminum alloy syntactic foam. Journal of Materials Engineering and Performance, 2019, 28: 4731-4739.

[17] Braszczyńska-Malik K N, Kamieniak J. AZ91 magnesium matrix foam composites with fly ash cenospheres fabricated by negative pressure infiltration technique. Materials Characterization, 2017, 128: 209-216.

[18] Movahedi N, Murch G E, Belova I V, et al. Effect of heat treatment on the compressive behavior of zinc alloy ZA27 syntactic foam. Materials, 2019, 12(5): 792.

[19] Bolat Ç, Gökşenli A. Fabrication optimization of Al 7075/ expanded glass syntactic foam by cold chamber die casting. Archives of Foundry Engineering, 2020, 20(3): 112-118.

[20] Kemény A, Leveles $B$, Károly D. Functional aluminium matrix syntactic foams filled with lightweight expanded clay aggregate particles. Materials Today: Proceedings, 2021, 45: 4229-4232.

[21] Kádár C, Máthis $\mathrm{K}$, Chmelík $\mathrm{F}$, et al. The deformation of expanded clay syntactic foams during compression characterized by acoustic emission. In book: Proceedings of the 11th International Conference on Porous Metals and Metallic Foams, TMS, Michigan, USA, 2019: 107-114.

[22] Gupta N, Rohatgi P K. Metal matrix syntactic foams. Lancaster, Pennsylvania, USA, DEStech Publications, Inc., 2014.

[23] Taherishargh M, Katona B, Fiedler T, et al. Fatigue properties of expanded perlite/aluminum syntactic foams. Journal of Composite Materials, 2017, 51(6): 773-781.

[24] Kádár C, Máthis $K$, Knapek M, et al. The Effect of matrix composition on the deformation and failure mechanisms in metal matrix syntactic foams during compression. Materials, 2017, 10(2): 196. 
[25] Rao D W, Yang Y W, Huang $Y$, et al. Microstructure and compressive properties of aluminum matrix syntactic foams containing $\mathrm{Al}_{2} \mathrm{O}_{3}$ hollow particles. Kovove Materialy-Metallic Materials, 2020, 58(6): 395-407.

[26] Puga H, Carneiro V H, Jesus $\mathrm{C}$, et al. Influence of particle diameter in mechanical performance of Al expanded clay syntactic foams. Composite Structures, 2018, 184: 698-703.

[27] Movahedi N, Murch G E, Belova I V, et al. Manufacturing and compressive properties of tube-filled metal syntactic foams. Journal of Alloys and Compounds, 2019, 822(6-7): 153465.

[28] Jung J, Kang J H, Kim S H, et al. Redox-reaction phenomenon in cenosphere reinforced aluminum alloy matrix syntactic foam. Journal of Alloys and Compounds, 2021, 862: 158686.

[29] Sahu S, Ansari M Z, Mondal D P. Microstructure and compressive deformation behavior of 2014 aluminium cenosphere syntactic foam made through stircasting technique. Materials Today: Proceedings, 2019, 25(4): 785-788.

[30] Broxtermann S, Su M M, Hao H, et al. Comparative study of stir casting and infiltration casting of expanded glassaluminium syntactic foams. Journal of Alloys and Compounds, 2020, 845(15-16): 155415.

[31] Vogiatzis C, Tsouknidas A, Kountouras D T, et al. Aluminumceramic cenospheres syntactic foams produced by powder metallurgy route. Materials \& Design, 2015, 85: 444-454.

[32] Akinwekomi A D, Adebisi J A, Adediran A A. Compressive characteristics of aluminum-fly ash syntactic foams processed by microwave sintering. Metallurgical and Materials Transactions A, 2019, 50: 4257-4260.

[33] Wongsa A, Sata V, Nuaklong P, et al. Use of crushed clay brick and pumice aggregates in lightweight geopolymer concrete. Construction and Building Materials, 2018, 188: 1025-1034.

[34] Singh R. Comparisons of process capability in cold chamber die casting of aluminium alloy. Proceedings of the National Academy of Sciences, India Section A: Physical Sciences, 2018, 88(2): 351-356.
[35] Wu M W, Li X B, Guo Z P, et al. Effects of process parameters on morphology and distribution of externally solidified crystals in microstructure of magnesium alloy die castings. China Foundry, 2018, 15(2): 139-144.

[36] Black J T, Kohser R A. De Garmos's materials and processes in manufacturing. USA, John Wiley and Sons, Inc, 2008: 316-320.

[37] Bolat Ç, Bilge G, Gökşenli A. An Investigation on the effect of heat treatment on the compression behavior of aluminum matrix syntactic foam fabricated by sandwich infiltration casting. Materials Research Ibero-american Journal of Materials, 2021, 24(2).

[38] Taherishargh M, Belova I V, Murch G E, et al. Low-density expanded perlite-aluminium syntactic foam. Materials Science and Engineering: A, 2014, 604: 127-134.

[39] ISO 13314 Standard: Mechanical testing of metals - Ductility testing - Compression test for porous and cellular metals, Genova, Switzerland, 2011.

[40] Katona B, Szlancsik A, Tábi T, et al. Compressive characteristics and low frequency damping of aluminum matrix syntactic foams. Materials Science and Engineering: A, 2019, 739: 140-148.

[41] Zhang L P, Zhao Y Y. Mechanical response of Al matrix syntactic foams produced by pressure infiltration casting. Journal of Composite Materials, 2007, 41(17): 2105-2117.

[42] Al-Sahlani K, Broxtermann S, Lell D, et al. Effects of particle size on the microstructure and mechanical properties of expanded glass-metal syntactic foams. Materials Science and Engineering: A, 2018, 728: 80-87.

[43] Taherishargh M, Belova I V, Murch G E, et al. Pumice/aluminum syntactic foam. Materials Science and Engineering: A, 2015, 635: 102-108. 